Check for updates

Cite this: RSC Adv., 2017, 7, 38519

\title{
MOF-derived Co/ZnOasilicalite-1 photocatalyst with high photocatalytic activity
}

\author{
Xiaobing Yang, $\uparrow^{a}$ Juan Chen, $\dagger^{\mathrm{b}}$ Huixian Lai, ${ }^{\mathrm{c}}$ Jiapeng Hu, ${ }^{a}$ Ming Fang ${ }^{\mathrm{d}}$ \\ and Xuetao Luo (D)*c
}

Metal doped $\mathrm{ZnO}$ supported on porous materials have unique and highly attractive properties and have drawn worldwide attention. Herein, we explored the synthesis of Co/ZIF-8@silicalite-1 catalysts containing different amounts of $\mathrm{Co}$ by using metal organic frameworks as precursors and silicalite-1 as support. Then Co/ZIF-8@ asilicalite-1 catalysts were calcined at $550^{\circ} \mathrm{C}$ to prepare the $\mathrm{Co} / \mathrm{ZnO}$ @ silicalite-1 photocatalysts. All samples were characterized by XRD, SEM, FT-IR and UV-vis diffuse reflectance spectra. The results show that the doping Co can increase the particle size of Co/ZIF- 8 and decrease the content of $\mathrm{Zn}$ in Co/ZIF-8@silicalite-1. When ZnO@silicalite-1 is doped with Co from $0 \%$ to $20 \%$, its band gap absorption is extended from 380 to $480 \mathrm{~nm}$ and a new band gap absorption at about $720 \mathrm{~nm}$ appears. The photocatalystic properties were investigated by degradation of rhodamine $B(\mathrm{RhB})$ aqueous solution under UV light. In the series of $\mathrm{Co} / \mathrm{ZnO}$ asilicalite-1 photocatalysts, 5Co/ZnO@asilicalite-1 shows the highest photocatalytic efficiency.

Received 25th May 2017

Accepted 1st August 2017

DOI: $10.1039 / c 7 r a 05863 b$

rsc.li/rsc-advances

organic pollutants. When $\mathrm{ZnO}$ catalyst is nanosized, it can

\section{Introduction}

In the past few years, semiconductor photocatalysts has attracted much attention as photocatalytic material in various organic pollution degradation and antimicrobial application. ${ }^{1}$ Until now, many semiconductor photocatalysts have been reported, such as $\mathrm{TiO}_{2},{ }^{2} \mathrm{Ag}_{3} \mathrm{PO}_{4},{ }^{3} \mathrm{SnO},{ }^{4} \mathrm{WO}_{3},{ }^{5} \mathrm{Bi}_{2} \mathrm{O}_{3},{ }^{6}$ and $\mathrm{ZnO} .{ }^{7}$ Among the various semiconductor photocatalysts, $\mathrm{ZnO}$ has been widely studied and extensively used in solar cells, photocatalysis, environmental remediation, and piezoelectric nanogenerators due to its high photocatalytic efficiency, excellent oxidative capacity, chemical stability, low cost and environmental sustainability. ${ }^{8}$

With the rapid development of science and technology, it is important to improve the photocatalytic activity of ZnO. The photocatalytic activity of $\mathrm{ZnO}$ is influenced by many factors. The most important factors are band gap and electron-hole pair recombination. Both of them are all affected by the particle size of the catalyst. For example, the photocatalytic reactions mainly occurred at the interface between the catalyst surfaces and

${ }^{a}$ College of Ecology and Resource Engineering, Wuyi University, Wuyishan, Fujian, 354300, China

${ }^{b}$ Department of Pharmacy, Zhongshan Hospital, Xiamen University, Xiamen, 361004, China

'Fujian Key Laboratory of Advanced Materials, College of Materials, Xiamen University, Xiamen, 361005, China. E-mail: xuetao@xmu.edu.cn

${ }^{d}$ Shaoxing Testing Institute of Quality and Technical Supervision, Shaoxing, Zhejiang, 312366, China

$\dagger$ Xiaobing Yang and Juan Chen contributed equally to this work. They are co-first authors. provide more surface area for the photocatalytic reactions. Further more, the recombination rate of the electron-hole pair in large size catalyst particles is higher than in small size catalyst particles. ${ }^{9}$ So many researchers have made effects to prepare the ZnO nanoparticles. ${ }^{10-13}$ However, the small size catalyst particles are easily to aggregate together and difficult to recycle. This restricts its application in photocatalytic systems. As a result, many researchers have made attempts to immobilize ZnO nanoparticles on solid support materials to overcome these drawbacks by synergistic effects, such as bentonite, ${ }^{14}$ graphene ${ }^{15}$ glass ${ }^{16}$ stainless steel, ${ }^{17}$ and zeolite. ${ }^{18}$

In the tradition research, the band gap of $\mathrm{ZnO}$ is $3.2 \mathrm{eV}$. It indicates that $\mathrm{ZnO}$ can be excited to produce the electron-hole pair to degrade the organic pollution under UV irradiation. ${ }^{19} \mathrm{In}$ order to improve the photocatalytic activity of $\mathrm{ZnO}$, many strategies have been used. For example, doping some ions on $\mathrm{ZnO}$ is a useful way, such as $\mathrm{Cr},{ }^{20} \mathrm{Fe},{ }^{21} \mathrm{Cu},{ }^{22} \mathrm{Ag},{ }^{23}$ and $\mathrm{Co}^{24}$ When $\mathrm{ZnO}$ is doped with some ions, it has more defects in its surface layer, which can make the photogenerated electrons and holes separation effectively.

In the last few years, metal-organic frameworks (MOFs), with the remarkable characteristics of well-defined channels and cavities of regular size and shape, have been widely studied and used for gas storage, ${ }^{25,26}$ small molecule separations, ${ }^{27}$ chemical catalysis and drug delivery, ${ }^{28,29}$ due to its large internal surface areas, uniform channels, (sub)nanometer-sized cavities, high thermal and chemical stability. ${ }^{30-34}$ Some attempts also have been made to explore the semiconducting properties of MOFs. Lin et al. suggested that band gaps of MOFs are between 1.0 and 
$5.5 \mathrm{eV}^{35,36}$ Bordiga et al. demonstrated that MOFs behave as metal oxide quantum dots. ${ }^{36}$ Zeolitic imidazolate frameworks (ZIFs), as a subfamily of metal organic frameworks (MOFs), are consisted of tetrahedral divalent metal ions $\left(\mathrm{Zn}^{2+}, \mathrm{Co}^{2+}\right)$ and an imidazole derivative. ${ }^{37,38}$ For example, $\mathrm{Zn}^{2+}$ can be connected by imidazolate linkers to form ZIF-8. ${ }^{39}$ And ZIF-67 is consisted of Co and imidazole. ${ }^{40} \mathrm{Zn}$ and Co also can be linked together by imidazolate linkers to form Co/ZIF-8. ${ }^{41}$ However, up to now, there are still no reports that use MOFs as precursor to synthesize the Co co-doped $\mathrm{ZnO}$ with porous structure by selfdoping. In this work, we used silicalite-1 as support to load the Co/ZIF-8 nanoparticles on its surface and synthesized the Co/ZnO@silicalite-1 photocatalyst by sintering method. Then we explored the influence of Co doping for the photocatalyst and the performance of $\mathrm{Co} / \mathrm{ZnO}$ @silicalite- 1 by degradation rhodamine B solution.

\section{Experimental}

\subsection{Chemicals}

Zinc nitrate hexahydrate $\left(\mathrm{Zn}\left(\mathrm{NO}_{3}\right)_{2} \cdot 6 \mathrm{H}_{2} \mathrm{O}, 98 \%\right)$, cobalt nitrate hexahydrate $\left(\mathrm{Co}\left(\mathrm{NO}_{3}\right)_{2} \cdot 6 \mathrm{H}_{2} \mathrm{O}, 99 \%\right)$, 2-methylimidazole (99\%) and methanol (99\%) were purchased from Sinopharm Chemical Reagent Co. Ltd. All chemicals were used as received without further purification. Deionized water was used throughout the experiments.

\subsection{Synthesis of Co/ZIF-8@silicalite-1 and Co/ ZnO@silicalite-1}

A series of Co/ZIF-8@silicalite-1 doped with different amount of Co were synthesized using a modification of a previously known procedure. $^{24}$ The synthesis protocol for 5Co/ZIF-8@silicalite-1 will be provided as an example. $20 \mathrm{mmol} \mathrm{g} \mathrm{Zn}\left(\mathrm{NO}_{3}\right)_{2} \cdot 6 \mathrm{H}_{2} \mathrm{O}$ and $1 \mathrm{mmol} \mathrm{Co}\left(\mathrm{NO}_{3}\right)_{2} \cdot 6 \mathrm{H}_{2} \mathrm{O}$ was dissolved into methanol (100 ml) containing $2 \mathrm{~g}$ silicalite-1. And $100 \mathrm{ml}$ methanol containing $80 \mathrm{mmol}$ 2-methylimidazole was added under agitation. After $30 \mathrm{~min}$, the solution was centrifuged and dried at $40{ }^{\circ} \mathrm{C}$. The process of preparing Co/ZIF-8@silicalite-1 is shown in Fig. 1. 2Co/ZIF-8@silicalite-1, 10Co/ZIF-8@silicalite-1 and $20 \mathrm{Co} / \mathrm{ZIF}-$ 8@silicalite- 1 were synthesized by the same procedure. In order to remove the organic parts of $\mathrm{Co} / \mathrm{ZIF}-8, \mathrm{Co} / \mathrm{ZIF}$ 8@silicalite- 1 was directly carbonized at $550{ }^{\circ} \mathrm{C}$ for $2 \mathrm{~h}$ under air atmosphere to prepare the $\mathrm{Co} / \mathrm{ZnO} @$ silicalite- 1 photocatalyst.

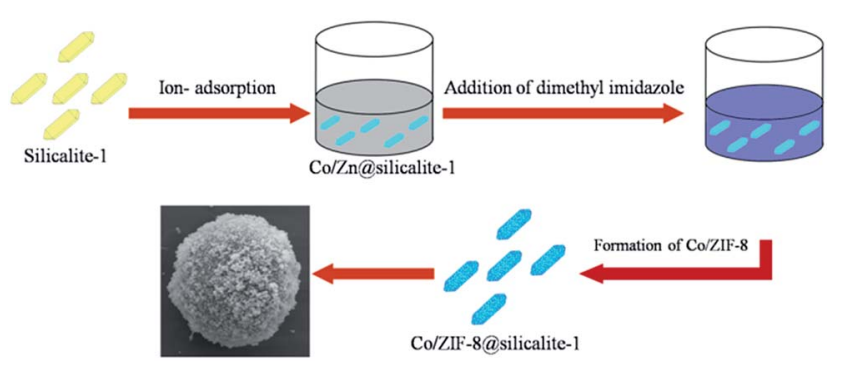

Fig. 1 The process of preparing Co/ZIF-8@asilicalite-1.

\subsection{Characterization of the products}

The morphology of all samples was observed on a Hitachi SU70 scanning microscope at accelerating voltage of $10 \mathrm{kV}$. The phase of the samples was tested by X-ray powder diffraction (XRD) on a Bruker-AxsD8 diffractometer using $\mathrm{Cu}-\mathrm{K}_{\alpha}$ radiation in the angular range $(2 \theta)$ from 5 to $60^{\circ}$, operated at $40 \mathrm{kV}$ and $40 \mathrm{~mA}$ with a scanning rate of $1 \% \mathrm{~min}$. The nitrogen adsorptiondesorption isotherms were measured by TriStar at $77 \mathrm{~K}$ after degassing the samples at $200{ }^{\circ} \mathrm{C}$ for $2 \mathrm{~h}$. Special surface areas were calculated from the results obtained for the nitrogen adsorption-desorption isotherms, according to Brunauer Emmett Teller (BET) equation. UV-vis absorption spectra of the Reactive Brilliant Red X-3B solution were determined using a UV1901 UV-visible spectrophotometer.

\subsection{Catalytic activity testing}

The catalytic activity of all samples was tested by degradation of rhodamine $\mathrm{B}(\mathrm{RhB})$ solution in an inclosed box. In the inclosed box, a $300 \mathrm{~W}$ lamp (irradiating UV light, $\lambda<400 \mathrm{~nm}$ ) was immobilized on the top and a magnetic stirrer was fixed at the bottom. The distance between the light and the reactor is $10 \mathrm{~cm}$. In each experiment, $100 \mathrm{ml}$ of rhodamine B aqueous solution ( $5 \mathrm{mg} \mathrm{L}^{-1}$ ) containing $0.2 \mathrm{~g}$ of catalyst was put into the reactor. Before the photocatalytic test was initiated, the solution was stirred continuously in the dark conditions for $30 \mathrm{~min}$ to ensure the adsorption-desorption equilibrium between RhB and the catalyst. Then, the UV light was turned on. During this irradiating time, five milliliters of the solution was withdrawn from the reactor every fifteen minutes and centrifuged to remove the photocatalyst before measuring to determine the residual dye concentration in solution. The fractional degradation efficiency $\left(D_{\mathrm{R}}\right)$ of RhB can be calculated by the following equation:

$$
D_{\mathrm{R}}=\frac{C_{0}-C_{t}}{C_{0}} \times 100 \%
$$

where $C_{0}$ is the initial concentration of $\mathrm{RhB}$ and $C_{t}$ is the concentration at a definite interval of time, respectively.

\section{Results and discussion}

The formation mechanism of Co/ZIF-8@silicalite-1 is shown in Fig. 2. In our previous work, it can be known that silicalite-1 has high surface area. ${ }^{42}$ And there are lots of pores in its structure, which are about $0.55 \mathrm{~nm}$. When silicalite- 1 disperses in ethanol containing $\mathrm{Co}^{2+}$ and $\mathrm{Zn}^{2+}$, it can absorb $\mathrm{Co}^{2+}$ and $\mathrm{Zn}^{2+}$ in its pores and surface $\left(\mathrm{Co}^{2+} / \mathrm{Zn}^{2+}\right.$ @silicalite-1). Then, dimethyl imidazole (2MI) is added into the ethanol and mixed with $\mathrm{Co}^{2+}$ / $\mathrm{Zn}^{2+}$ @silicalite-1, it can combine the $\mathrm{Co}^{2+}$ and $\mathrm{Zn}^{2+}$ absorbed in the surface of silicalite- 1 and format Co/ZIF-8 structure on the surface of silicalite-1.

Fig. 3 is the XRD patterns of Co/ZIF-8@silicalite-1 catalysts. Fig. $3 \mathrm{a}$ is the XRD patterns of silicalite-1. From Fig. 3a, it can be seen that silicalite- 1 shows characteristic peaks at $7.98^{\circ}, 8.82^{\circ}$, $13.24^{\circ}, 13.94^{\circ}, 14.80^{\circ}, 15.53^{\circ}, 15.89^{\circ}, 17.79^{\circ}, 20.37^{\circ}, 23.18^{\circ}$ and $24.46^{\circ}$, which are ascribable to (101), (020), (300), (012), (301), (202), (040), (031), (501), (151) and (303) reflections of silicalite-1 


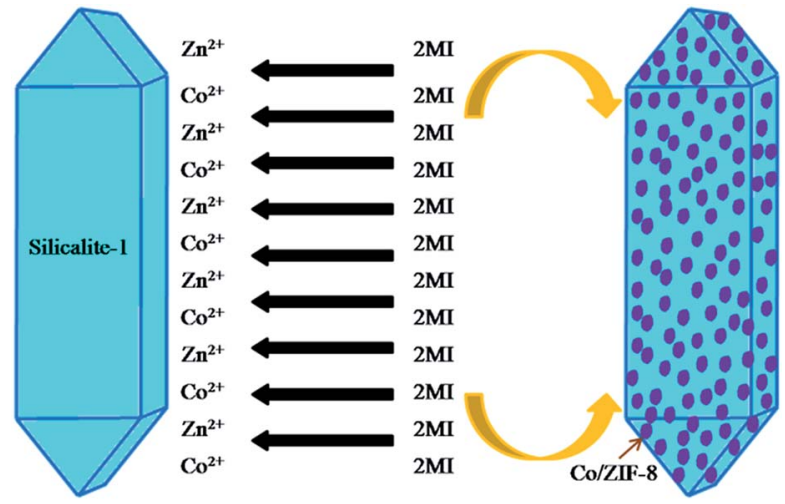

Fig. 2 The formation mechanism of Co/ZIF-8asilicalite-1.

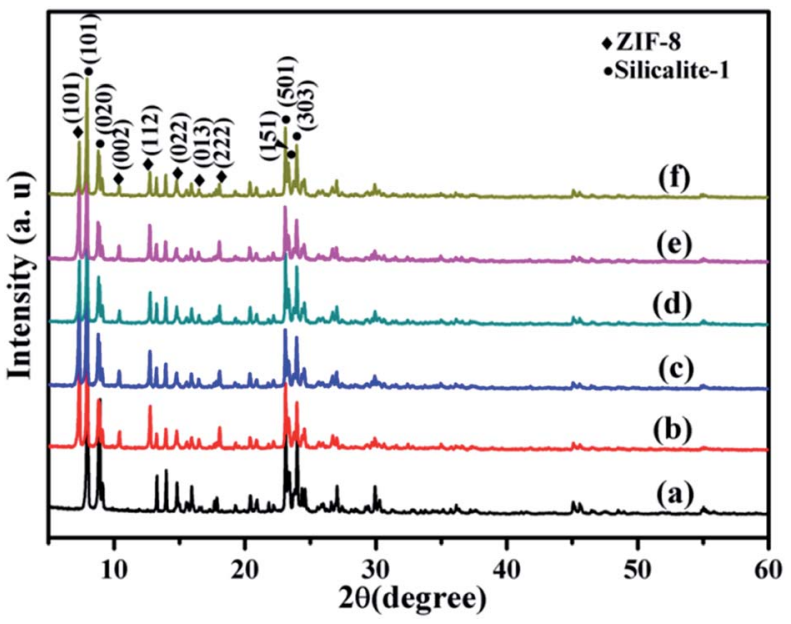

Fig. 3 XRD patterns of (a) silicalite-1, (b) ZIF-8@asilicalite-1, (c) 2Co/ ZIF-8@silicalite-1, (d) 5Co/ZIF-8@silicalite-1, (e) 10Co/ZIF-8@silicalite-1, (f) 20Co/ZIF-8@silicalite-1

(JCPDS: 48-0136). ${ }^{43}$ Fig. 3b is the XRD patterns of ZIF-8@silicalite1. It can be seen that ZIF-8@silicalite-1 exhibits new peaks at $14.73^{\circ}, 16.45^{\circ}, 18.06^{\circ}$, which are ascribable to (101), (002), (112) reflections of ZIF-8 (JCPDS: $89-3739) .{ }^{44}$ Fig. $3 \mathrm{c}$ and e-g are the XRD patterns of 2Co/ZIF-8@silicalite-1, 5Co/ZIF-8@silicalite-1, 10Co/ ZIF-8@silicalite-1 and 20Co/ZIF-8@silicalite-1. It can be seen that the diffraction peaks of Co/ZIF-8@silicalite-1 doping with different amounts of Co are almost the same with ZIF8@silicalite-1. It indicates that the doping of Co does not change the diffraction peaks of ZIF-8@silicalite-1.

Fig. 4 is the SEM images of ZIF-8@silicalite-1 and Co/ZIF8@silicalite-1 samples. Fig. $4 \mathrm{a}$ is the SEM images of ZIF8@silicalite-1. It can be seen that the surface of silicalite-1 is coated with a layer of ZIF-8 nanoparticles. The high magnification image (Fig. 4b) shows that ZIF-8 nanoparticles, with a narrow size distribution ranging from 100 to $200 \mathrm{~nm}$, are clearly observed. Fig. $4 \mathrm{c}-\mathrm{f}$ are the high magnification images of 2Co/ZIF8@silicalite-1, 5Co/ZIF-8@silicalite-1, 10Co/ZIF-8@silicalite-1, 20Co/ZIF-8@silicalite-1. It can be seen that when the content of Co increase from 0 to 20, the average size of Co/ZIF-8 increases from 150 to $350 \mathrm{~nm}$. It is in accordance with Zaręba's report. ${ }^{41}$
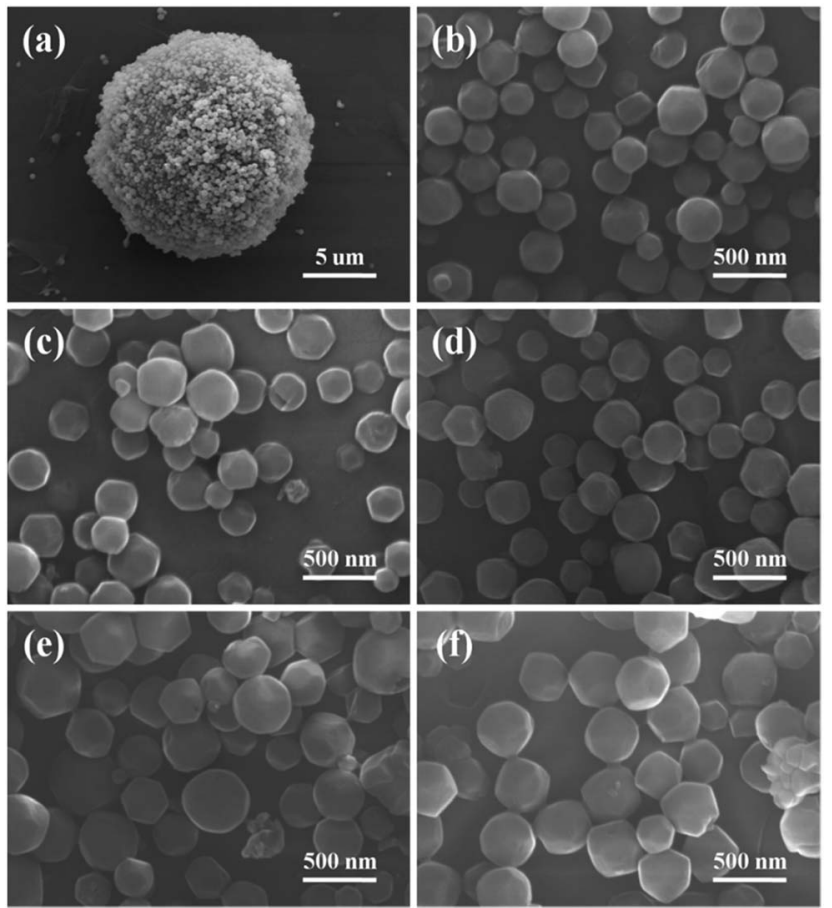

Fig. 4 SEM images of (a and b)ZIF-8@asilicalite-1, (c) 2Co/ZIF-8@silicalite-1, (d) 5Co/ZIF-8@asilicalite-1, (e) 10Co/ZIF-8@silicalite-1, (f) 20Co/ZIF-8@silicalite-1.

To obtain the $\mathrm{Co} / \mathrm{ZnO} @$ silicalite-1 photocatalyst, Co/ZIF8@silicalite- 1 catalysts were calcined at $550{ }^{\circ} \mathrm{C}$ for $2 \mathrm{~h}$ under air atmosphere to remove the organic ligand. Fig. 5 is the XRD patterns of $\mathrm{Co} / \mathrm{ZnO} @$ silicalite-1 photocatalysts. Fig. 5a is the XRD patterns of silicalite-1, which is the same with Fig. 3a. From Fig. 5, it can be seen that after sintering, the characteristic peaks of ZIF-8 is disappeared. There are appeared new peaks at $31.77^{\circ}, 34.42^{\circ}, 36.25^{\circ}, 47.54^{\circ}$ and $56.59^{\circ}$, which are corresponding to (100), (002), (101), (103) and (110) reflections of ZnO (JCPDS: 36-1451). It indicates that ZIF-8 transforms into

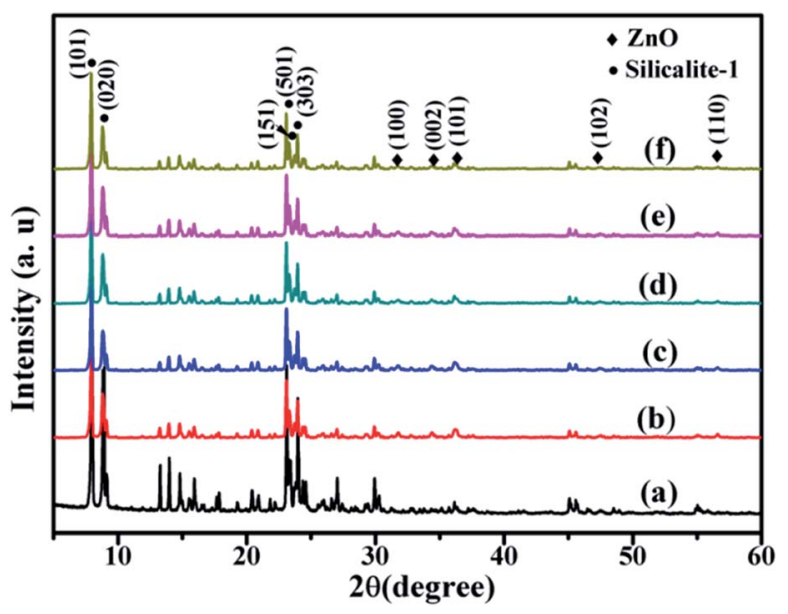

Fig. 5 XRD patterns of (a) silicalite-1, (b) ZnOasilicalite-1, (c) $2 \mathrm{Co} /$ ZnO@silicalite-1, (d) 5Co/ZnO@silicalite-1, (e) 10Co/ZnOasilicalite-1, (f) $20 \mathrm{Co} / \mathrm{ZnO}$ asilicalite-1. 


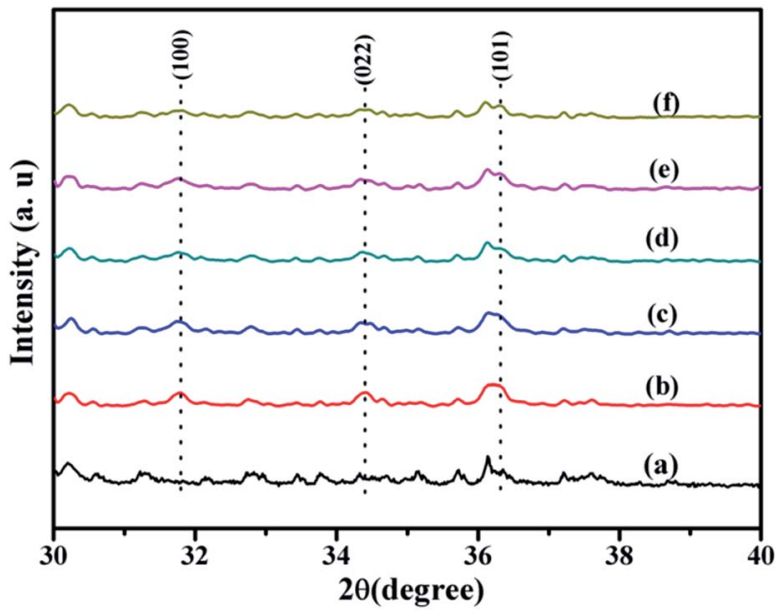

Fig. 6 XRD patterns of (a) silicalite-1, (b) ZnOasilicalite-1, (c) 2Co/ ZnO@silicalite-1, (d) 5Co/ZnO@silicalite-1, (e) 10Co/ZnO@silicalite-1, (f) $20 \mathrm{Co} / \mathrm{ZnO}$ asilicalite-1.

ZnO. Fig. 5c-f are the XRD patterns of ZnO@silicalite-1 coated with different amounts of Co. The doping of Co does not change the characteristic peaks of $\mathrm{ZnO} @$ silicalite-1.

Fig. 6 is the magnification of XRD patterns of Co/ZnO@silicalite-1 photocatalysts from $30^{\circ}$ to $40^{\circ}$. It can be found that there are existing distinct characteristic peaks at $31.77^{\circ}, 34.42^{\circ}, 36.25^{\circ}$ for ZnO@silicalite-1 (Fig. 6b). When $\mathrm{ZnO}$ @silicalite-1 is doped with $2 \% \mathrm{Co}$, the intensity of characteristic peaks of $\mathrm{ZnO}$ is weakened (Fig. 6c). With the increase of Co from $2 \%$ to $20 \%$, the intensity of characteristic peaks of $\mathrm{ZnO}$ decreases more. It indicates that the doping of Co can restrain the formation of ZIF-8.

Fig. 7 is the SEM images of $\mathrm{Co} / \mathrm{ZnO} @$ silicalite-1 photocatalysts. After sintering, the structure of Co/ZIF-8 collapses. Fig. 7a and $b$ are the SEM images of ZnO@silicalite-1. It can be seen that the collapsed nanoparticles are about $50 \mathrm{~nm}$ and adheres on the surface of silicalite-1. With the increase of Co content, the collapsed nanoparticles increase too (from 50 to $200 \mathrm{~nm}$ ). From Fig. 5 and 6, we can know that the nanoparticles are $\mathrm{ZnO}$.

The FT-IR spectra of silicalite-1, ZnO@silicalite-1 and Co/ZnO@silicalite-1 with different Co content are shown in Fig. 8. From Fig. 8, it can be found that all samples show vibration bands at around 446, 546, 781 and $1103 \mathrm{~cm}^{-1}$. The band at $446 \mathrm{~cm}^{-1}$ is attributed to the bending vibration of $\mathrm{SiO}_{4}{ }^{38}$ The band at $546 \mathrm{~cm}^{-1}$ is corresponding to the five membered ring of pentasil zeolite structure. ${ }^{23}$ The bands at $1103 \mathrm{~cm}^{-1}$ and $781 \mathrm{~cm}^{-1}$ are attributed to the internal asymmetric stretching vibration and external symmetric stretching of Si-O-Si bonds, respectively. Fig. 8b is the FT-IR spectra of ZnO@silicalite-1. It can be seen that there is existing new band at $459 \mathrm{~cm}^{-1}$, which is belonged to the characteristic band of ZnO. When $\mathrm{ZnO} @$ silialite-1 is doped with Co, it shows band at $671 \mathrm{~cm}^{-1}$ (Fig. 8c), which is ascribed to $\mathrm{Co}-\mathrm{O}$ bond.

Fig. 9 shows the UV-vis diffuse reflectance spectra for silicalite-1, ZnO@silicalite-1, $\mathrm{Co} / \mathrm{ZnO} @$ silicalite-1 containing different amounts of Co. Silicalite- 1 just shows a weak band gap
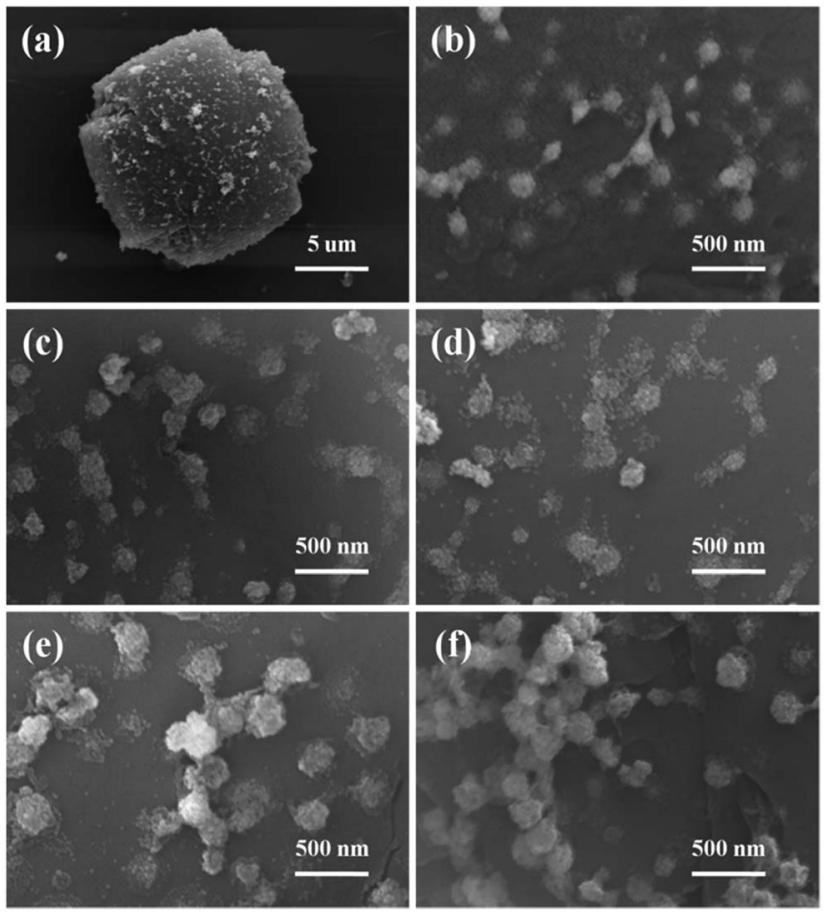

Fig. 7 SEM images of (a and b) ZnOasilicalie-1, (c) 2Co/ZnOasilicalite-1, (d) 5Co/ZnOasilicalite-1, (e) $10 \mathrm{Co} / \mathrm{ZnO}$ asilicalite-1, (f) 20Co/ ZnO@silicalite-1.

absorption at about $300 \mathrm{~nm}$. When silicalite-1 is coated with $\mathrm{ZnO}$ nanoparticles, it shows a highly band gap absorption at about $388 \mathrm{~nm}$. When $\mathrm{ZnO@silicalite-1} \mathrm{is} \mathrm{doped} \mathrm{with} 2 \% \mathrm{Co}$, its band gap absorption is extended into the visible light region (about $450 \mathrm{~nm}$ ). With the increase of the doping Co content, the band gap absorption of $\mathrm{Co} / \mathrm{ZnO} @$ silicalite-1 is extended from 450 to $480 \mathrm{~nm}$. Except that, there is appearing new band gap absorption at about $720 \mathrm{~nm}$. It is probably due to the $\mathrm{Zn}_{1-x} \mathrm{Co}_{x} \mathrm{O}$ solid solution formation. ${ }^{45,46}$ And the intensity of the band gap absorption also enhances with the increase of Co content.

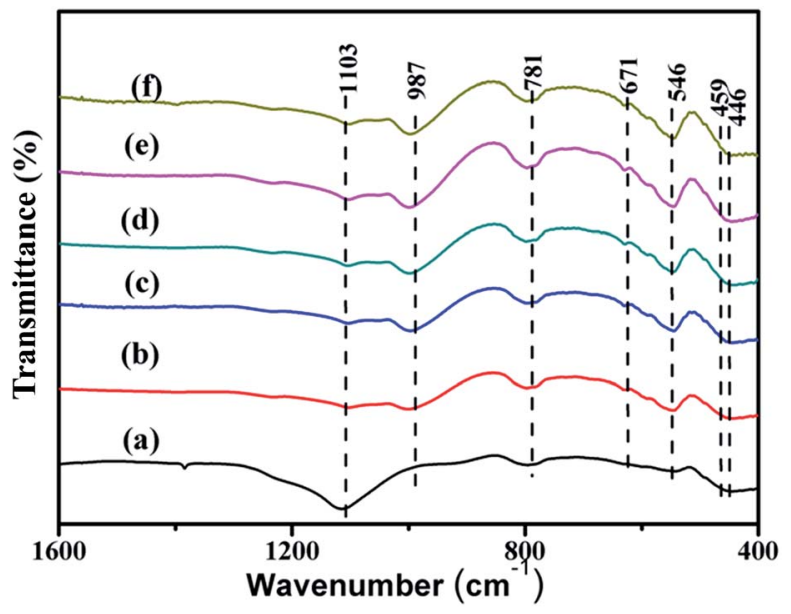

Fig. 8 FT-IR spectra of (a) silicalite-1, (b) ZnOasilicalite-1, (c) 2Co/ ZnOasilicalite-1, (d) 5Co/ZnO@ silicalite-1, (e) 10Co/ZnO@ asilicalite-1, (f) 20Co/ZnO@ asilicalite-1. 


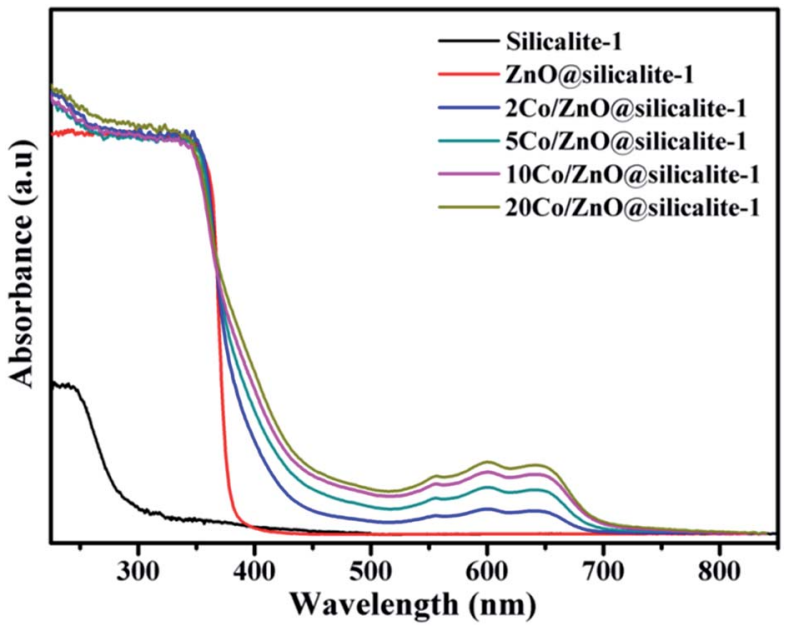

Fig. 9 UV-vis absorption spectra of photocatalysts.

To evaluate the photocatalytic activity of all samples, degradation rhodamine $(\mathrm{RhB})$ was chosen as a model organic dye. The results of RhB removal by photocatalysts are shown in Fig. 10a. In order to eliminate the influence of the adsorption of photocatalyst, all experiments were operated in the dark for $30 \mathrm{~min}$. After $30 \mathrm{~min}$ of continuously stirring in the dark, $20.4 \%$ of RhB is absorbed by silicate-1. It is attributed the high specific surface area of silicalite- $1 .{ }^{47}$ When silicalite- 1 is coated with $\mathrm{ZnO}$ nanoparticles, it can absorb $14.8 \%$ of RhB. The decrease of its adsorptive property is attributed to the decrease of silicalite- 1 . With the increase of Co content, the adsorptive property of photocatalyst decreases. It may be caused by the increase of Co in the photocatalyst and the decrease of silicalite- 1 content. Then, all experiments are exposed under the UV light. After 90 min of UV light irradiation, only $5.4 \%$ of RhB is degraded by itself under the UV light. And silicalite-1 just degrades $6.3 \%$ of RhB. Silicalite-1 almost has not photocatalytic properties. When silicalite-1 is coated with $\mathrm{ZnO}$ nanoparticles, it can degrade 98.5\% of RhB. When ZnO@silicalite-1 is doped with $2 \% \mathrm{Co}$, it can degrade $90.7 \%$ of RhB. The photocatalytic efficiency of $2 \mathrm{Co} /$ $\mathrm{ZnO}$ @silicalite-1 is lower than the photocatalytic efficiency of ZnO@silicalite-1, which is attributed to the significantly decreasing $\mathrm{ZnO}$ (Fig. 6). However, the photocatalytic efficiency of $5 \mathrm{Co} / \mathrm{ZnO} @$ silicalite- 1 is $94.0 \%$, and then the photocatalytic efficiency of $\mathrm{Co} / \mathrm{ZnO} @$ silicalite-1 decreases with the increase of Co content. It indicates the doping Co can enhance the photocatalytic efficiency of $\mathrm{ZnO} @$ silicalite-1 and 5Co/ZnO@silicalite-
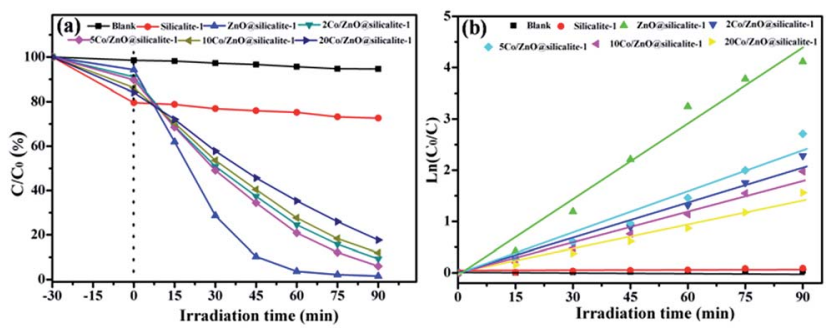

Fig. 10 Photocatalytic degradation (a) and kinetics (b) of all samples.

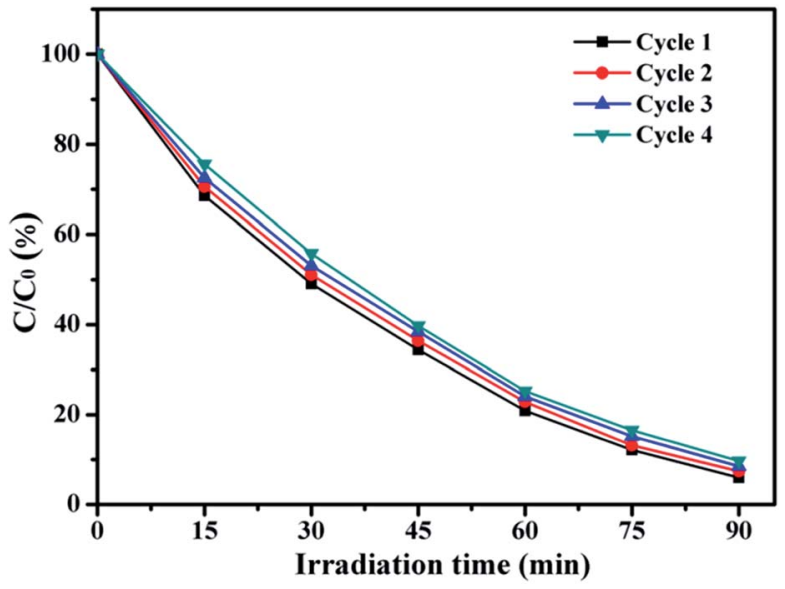

Fig. 11 Four photocatalytic degradation cycles of RhB using $5 \mathrm{Co} /$ ZnO@silicalite-1 photocatalyst under UV light.

1 has the highest photocatalytic efficiency. The photocatalysis degradation kinetic reaction can be described by $\ln \left(C_{0} / C\right)=k t$, where $k$ is a pseudo-first-rate kinetic constant and $t$ is the irradiation time. And the results are shown in Fig. 10b. The calculated $k$ value for 2Co/ZnO@silicalite-1, 10Co/ZnO@silicalite-1 and 20Co/ZnO@silicalite-1 is $0.023,0.02$ and $0.016 \mathrm{~min}^{-1}$, respectively. For $5 \mathrm{Co} / \mathrm{ZnO} @$ silicalite- 1 , the calculated $k$ value is $0.027 \mathrm{~min}^{-1}$, which is higher than 2Co/ZnO@silicalite-1, 10Co/ ZnO@silicalite-1 and 20Co/ZnO@silicalite-1. The photocatalysis activity of the composite is improved greatly. For ZnO@silicalite-1, its $k$ value is $0.05 \mathrm{~min}^{-1}$, which it higher than Co doped ZnO@silicalite-1. It is attributed to the decrease of $\mathrm{ZnO}$ content.

In order to investigate the stability of photocatalytic performance of $\mathrm{Co} / \mathrm{ZnO} @$ silicalite-1, 5Co/ZnO@silicalite-1 was chosen to degrade RhB in four repeated cycles. The results are shown in Fig. 11. It can be found that after four photocatalytic degradation cycles, the photocatalytic efficiency of $5 \mathrm{Co} /$ $\mathrm{ZnO}$ @silicalite-1 reduces only by $3.6 \%$. It may be the reason that $5 \mathrm{Co} / \mathrm{ZnO}$ nanoparticles adhere tightly on the surface of silicalite-1.

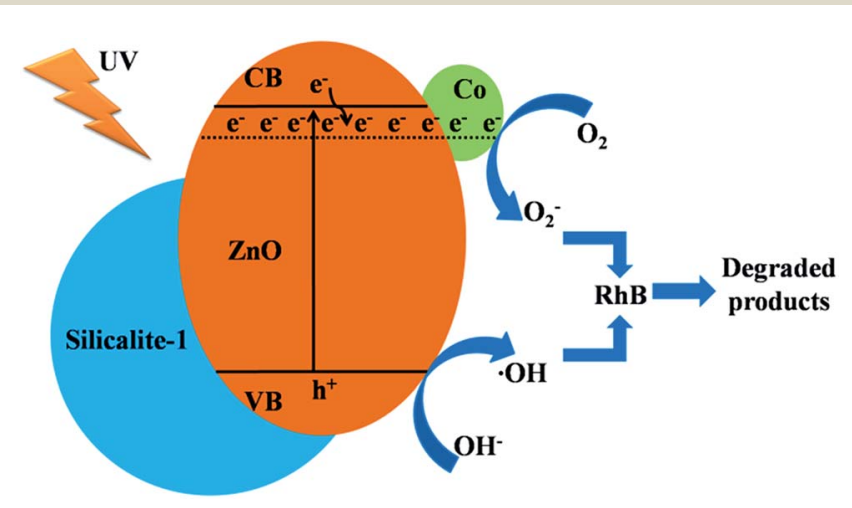

Fig. 12 The schematic illustration of $\mathrm{Co} / \mathrm{ZnO}$ (asilicalite-1 for RhB degradation under UV light. The solid lines indicate $\mathrm{VB}$ and $\mathrm{CB}$ of $\mathrm{ZnO}$ whereas dashed lines indicate the change in $V B$ and $C B$ energies on Co/ZnO@silicalite-1. 
Fig. 12 shows the schematic illustration of $\mathrm{Co} /$ ZnO@silicalite-1 for RhB degradation under UV light. Co/ZnO nanoparticles adhere tightly on the surface of silicalite- 1 . Silicalite-1 has high surface area. It can absorb RhB molecules on its surface or pores. When $\mathrm{Co} / \mathrm{ZnO}$ is irradiated by UV light, it can generate electrons and holes. $\mathrm{O}_{2}$ can capture electrons from the conduction band to form $\mathrm{O}^{2-}$. And $\mathrm{OH}^{-}$can lose its electrons from the valence band to form ${ }^{\circ} \mathrm{OH}$. The generated $\mathrm{O}_{2}{ }^{-}$ and ${ }^{\circ} \mathrm{OH}$ can convert $\mathrm{RhB}$ molecules into $\mathrm{CO}_{2}, \mathrm{H}_{2} \mathrm{O}$ and so on.

\section{Conclusions}

This paper reports a sample and rapid way to synthesize Co/ ZnO@silicalite- 1 photocatalysts and explores the influence of Co for its properties. The results show that the doping Co can restrain the synthesis of $\mathrm{ZnO}$. But the band gap absorption of the photocatalyst is extended into the visible energy region and there is also appearing an new band gap absorption at about $720 \mathrm{~nm}$. When $\mathrm{Co} / \mathrm{ZnO} @$ silicalite-1 photocatalysts were used to degrade RhB solution, 5Co/ZnO@silicalite-1 exhibited the highest photocatalytic activity (94.0\%). Moreover, 5Co/ZnO@silicalite-1 has high photostability. It has potential to be used in the treatment of dye pollutants.

\section{Acknowledgements}

The authors grateful acknowledge financial supported by the Scientific Technological Innovation Platform of Fujian Province (2006L2003). Especially, we thank very much Professor Bizhou Lin from Huaqiao University of China for the helpful discussions.

\section{Notes and references}

1 J. H. Jun, H. Seong, K. Cho, B.-M. Moon and S. Kim, Ceram. Int., 2009, 35, 2797-2801.

2 C. Yi, X. Li, J. Luo, S. M. Zakeeruddin and M. Grätzel, $A d v$. Mater., 2016, 28, 2964-2970.

3 H. Katsumata, T. Sakai, T. Suzuki and S. Kaneco, Ind. Eng. Chem. Res., 2014, 53, 8018-8025.

4 Y. Tang, D. Wu, S. Chen, F. Zhang, J. Jia and X. Feng, Energy Environ. Sci., 2013, 6, 2447-2451.

5 P. M. Rao, L. Cai, C. Liu, I. S. Cho, C. H. Lee, J. M. Weisse, P. Yang and X. Zheng, Nano Lett., 2014, 14, 1099-1105.

6 L. An, G. Wang, Y. Cheng, L. Zhao, F. Gao and Y. Tian, Res. Chem. Intermed., 2014, 41, 7449-7461.

7 D. Liu, Y. H. Lv, M. Zhang, Y. F. Liu, Y. Y. Zhu, R. L. Zong and Y. F. Zhu, J. Mater. Chem. A, 2014, 2, 15377-15388.

8 M. S. Gohari and A. H. Yangjeh, RSC Adv., 2016, 6, 24022413.

9 D. Virovska, D. Paneva, N. Manolova, I. Rashkov and D. Karashanova, Mater. Sci. Eng., C, 2016, 60, 184-194.

10 J. Hou, L. Miao, C. Wang, P. Wang, Y. Ao, J. Qian and S. Dai, J. Hazard. Mater., 2014, 276, 164-170.

11 L. R. Heggelund, M. Diez-Ortiz, S. Lofts, E. Lahive, K. Jurkschat, J. Wojnarowicz, N. Cedergreen, D. Spurgeon and C. Svendsen, Nanotoxicology, 2013, 8, 559-572.
12 D. Y. Son, K. H. Bae, H. S. Kim and N. G. Park, J. Phys. Chem. C, 2015, 119, 10321-10328.

13 S. B. Dkhil, D. Duché, M. Gaceur, A. K. Thakur, F. B. Aboura, L. Escoubas, J. J. Simon, A. Guerrero, J. Bisquert, G. GarciaBelmonte, Q. Bao, M. Fahlman, C. Videlot-Ackermann, O. Margeat and J. Ackermann, Adv. Energy Mater., 2014, 4, 1400805.

14 H. Xu, T. Yu and J. Liu, Mater. Lett., 2014, 117, 263-265.

15 E. Rokhsat and O. Akhavan, Appl. Surf. Sci., 2016, 371, 590595.

16 C.-L. Hsu, Y.-D. Gao, Y.-S. Chen and T.-J. Hsueh, Sens. Actuators, B, 2014, 192, 550-557.

17 T. T. Vu, L. del Río, T. Valdés-Solís and G. Marbán, J. Hazard. Mater., 2013, 246-247, 126-134.

18 Z. Liu, Z. Liu, T. Cui, J. Li, J. Zhang, T. Chen, X. Wang and X. Liang, Chem. Eng. J., 2014, 235, 257-263.

19 W. Yu, J. Zhang and T. Peng, Appl. Catal., B, 2016, 181, 220227.

20 K. Pinkaew, G. Yang, T. Vitidsant, Y. Jin, C. Zeng, Y. Yoneyama and N. Tsubaki, Fuel, 2013, 111, 727-732.

21 Y. Liu, L. Sun, J. Wu, T. Fang, R. Cai and A. Wei, Mater. Sci. Eng., B, 2015, 194, 9-13.

22 J. Ma, K. Wang, L. Li, T. Zhang, Y. Kong and S. Komarneni, Ceram. Int., 2015, 41, 2050-2056.

23 P. Fageria, S. Gangopadhyay and S. Pande, RSC Adv., 2014, 4, 24962-24972.

24 M. Li, K. Chang, T. Wang, L. Q. Liu, H. B. Zhang, P. Li and J. H. Ye, J. Mater. Chem. A, 2015, 3, 13731-13737.

25 J. G. Wu, T. Fang, R. Cai, S. Y. Li, Y. Wang, C. E. Zhao and A. Wei, RSC Adv., 2016, 6, 4245-4150.

26 S. Liu, L. Sun, F. Xu, J. Zhang, C. Jiao, F. Li, Z. Li, S. Wang, Z. Wang, X. Jiang, H. Zhou, L. Yang and C. Schick, Energy Environ. Sci., 2013, 6, 818-823.

27 S. Yang, F. Ye, Q. Lv, C. Zhang, S. Shen and S. Zhao, J. Chromatogr. A, 2014, 1360, 143-149.

28 K. Na, K. M. Choi, O. M. Yaghi and G. A. Somorjai, Nano Lett., 2014, 14, 5979-5983.

29 C. O. Tavra, E. F. Baxter, T. Tian, T. D. Bennett, N. K. H. Slater, A. K. Cheetham and D. F. Jimenez, Chem. Commun., 2015, 51, 13878-13881.

30 H. C. J. Zhou and S. Kitagawa, Chem. Soc. Rev., 2014, 43, 5415-5418.

31 B. S. Barros, J. Chojnacki, A. A. M. Soares, J. Kulesza, L. L. D. Luz and S. A. Júnior, Mater. Chem. Phys., 2015, 162, 364-371.

32 Y. Yang, K. Shen, J. Z. Lin, Y. Zhou, Q. Y. Liu, C. Huang, H. N. Abdelhamid, Z. Q. Zhang and H. Chen, RSC Adv., 2016, 6, 45475-45481.

33 I. M. Hauptvogel, R. Biedermann, N. Klein, I. Senkovska, A. Cadiau, D. Wallacher, R. Feyerherm and S. Kaskel, Inorg. Chem., 2011, 50, 8367-8374.

34 J. Kulesza, B. S. Barros, S. A. Júnior, C. A. F. D. Oliveira, D. M. D. A. Melo and J. Chojnacki, Mater. Chem. Phys., 2014, 143, 1522-1527.

35 C. K. Lin, D. Zhao, W. Y. Gao, Z. Yang, J. Ye, T. Xu, Q. Ge, S. Ma and D. J. Liu, Inorg. Chem., 2012, 51, 9039-9044. 
36 S. Bordiga, C. Lamberti, G. Ricchiardi, L. Regli, F. Bonino, A. Damin, K. P. Lillerud, M. Bjorgen and A. Zecchina, Chem. Commun., 2004, 2300-2301.

37 Y. Pan, Y. Liu, G. Zeng, L. Zhao and Z. Lai, Chem. Commun., 2011, 47, 2071-2073.

38 J. Qian, F. Sun and L. Qin, Mater. Lett., 2012, 82, 220-223.

39 N. L. Torad, M. Hu, Y. Kamachi, K. Takai, M. Imura, M. Naito and Y. Yamauchi, Chem. Commun., 2013, 49, 2521-2523.

40 N. L. Torad, R. R. Salunkhe, Y. Li, H. Hamoudi, M. Imura, Y. Sakka, C. C. Hu and Y. Yamauchi, Chem.-Eur. J., 2014, 20, 7895-7900.

41 J. K. Zaręba, M. Nyk and M. Samoć, Cryst. Growth Des., 2016, 16, 6419-6425.
42 X. B. Yang, C. H. Gan, H. P. Xiong, L. Q. Huang and X. T. Luo, RSC Adv., 2016, 6, 105737-105743.

43 X. B. Yang, L. Q. Huang, J. T. Li, X. Y. Tang and X. T. Luo, RSC Adv. , 2017, 7, 12224-12230.

44 P. Neelakanda, E. Barankova and K.-V. Peinemann, Microporous Mesoporous Mater., 2016, 220, 215-219.

45 J. Kegel, J. Halpin, F. Laffir, I. M. Povey and M. E. Pemble, CrystEngComm, 2017, 19, 1938-1946.

46 A. Šutka, T. Käämbre, R. Pärna, I. Juhnevica, M. Maiorov, U. Joost and V. Kisand, Solid State Sci., 2016, 56, 54-62.

47 B. E. Kayaalp, Y. J. Lee, A. Kornowski, S. Gross, M. D. Arienzo and S. Mascotto, RSC Adv., 2016, 6, 90401-90409. 